2. Association between use of new walking and cycling infrastructure and meeting physical activity guidelines.

Models were adjusted for demographic variables. Cohort data were additionally adjusted for baseline physical activity and scheme.

Results The new routes were associated with increased use (median increase in cyclists $=52 \%$, pedestrians $=38 \%$ $(\mathrm{p}<0.001))$. Large relative increases in users were found where baseline levels were low (e.g. double cycling $\mathrm{OR}=0.47,95 \%$ $\mathrm{CI}=0.26,0.74$ for each 10,000 baseline cyclists). Use of the new routes was associated with meeting physical activity guidelines in both the cross-sectional pre-post and longitudinal evaluations (compared to non-users, 1-yr follow-up users $\mathrm{OR}=2.09,95 \% \mathrm{CI}=1.38-3.25 ; 2$-yr follow-up users $\mathrm{OR}=2.04$, $95 \% \mathrm{CI}=1.40,3.03)$ ).

Conclusion Creating new walking and cycling infrastructure may help to increase levels of population physical activity and places with existing low levels of walking and cycling could see the largest relative increases. 'Routine' and academic research evaluations involve trade-offs between scale, representativeness of sample and ability to capture withinparticipant change. Combining findings across data sources can help to understand the impacts of complex interventions on health.

\section{OP90 AN EVALUATION OF THE IMPACT OF THE 20MPH SPEED LIMITS IN THE CITY OF EDINBURGH ON ROAD TRAFFIC CASUALTY AND COLLISION RATES}

${ }^{1}$ GF Nightingale ${ }^{*},{ }^{2} \mathrm{AJ}$ Williams, ${ }^{3} \mathrm{~J}$ Woodcock, ${ }^{4} \mathrm{P}$ Kelly, ${ }^{3} \mathrm{~K}$ Kokka, ${ }^{3} \mathrm{~A}$ Abbas, ${ }^{1} \mathrm{R}$ Jepson. ${ }^{1}$ Health in Social Science, University of Edinburgh, Edinburgh, UK; ${ }^{2}$ School of Medicine, University of St Andrews, St Andrews, UK; ${ }^{3}$ Centre for Diet and Activity Research, University of Cambridge, Cambridge, UK; ${ }^{4}$ Physical Activity for Health Research Centre, University of Edinburgh, Edinburgh, UK

\subsection{6/jech-2020-SSMabstracts.88}

Background The City of Edinburgh implemented 20mph speed limits on most of the streets (an increase from 50\% to 80\%) in the city between April 2016 and March 2018. This paper is part of the research undertaken by the 'Is Twenty Plenty for Health?' project team which examines the impact of the $20 \mathrm{mph}$ speed limit policy in the City of Edinburgh. This paper assesses, specifically, the impact of the speed limits on the average vehicular speed and volume in the City, and the road traffic collision and casualty rates. Police recorded data (road traffic collisions and casualties), and the City of Edinburgh's street survey data are used in this study.

Methods In this paper we calculate vehicular speed and volume summaries, and the average annual rate for collisions and casualties for selected subgroups. In addition, we calculate the percentage difference in annual rates before and after the $20 \mathrm{mph}$ speed limits (un-adjusted and adjusted for secular trend) for various street categories. The observed reduction in collisions (overall) is compared with that predicted from Elvik's power model.

Finally, we construct a regression model with key explanatory variables treatment (implementation zone vs control zone), time (adhering to the stepped wedge nature of the implementation), and an interaction term constructed from the two latter variables. The dependent variable is the number of collisions (and separately, casualties) and the model coefficient of the interaction term is the 'difference in differences' estimator.

Results Our results show that there was a statistically significant reduction of in average speed in the City $(1.34 \mathrm{mph})$ since the speed limit implementation and that there was no significant change in vehicular volume. We identified a reduction in road traffic collisions post speed limit implementation and a reduction in road traffic casualties in key vulnerable groups such as children (a provisional, un-adjusted 39\% reduction in casualty rate).

Conclusion In this paper, we reveal the changes in vehicular speed and volume post $20 \mathrm{mph}$ speed limits and also present changes in road traffic collisions and casualties. In addition we apply statistical methods to evaluate the impact of the speed limits in a natural experiment context. This study is important not only to public health and city planning officials, but to academics involved in natural experiment evaluations.

\section{Friday 11 September Pregnancy II}

\section{OP91 DID ENGLAND'S TEENAGE PREGNANCY STRATEGY REDUCE PREGNANCY RATES IN ENGLAND? EVALUATING A POLICY USING TWO NATURAL EXPERIMENTAL METHODS}

AJ Baxter*, R Dundas, F Popham, P Craig. MRC/CSO Social and Public Health Sciences Unit, University of Glasgow, Glasgow, UK

\subsection{6/jech-2020-SSMabstracts.89}

Background The Teenage Pregnancy Strategy was published in July 1999 with the aim halving under-18 pregnancy rates in ten years. The strategy came to an end in 2010 with the UK's change of government. Overall costs of implementation are estimated around $£ 280 \mathrm{~m}$. From 1999-2014 rates of pregnancy to women aged under 18 fell by more than $50 \%$. Hailed as a unique, nation-wide, comprehensive, evidencebased intervention, the strategy has been promoted as a reproducible model for other countries with high teenage pregnancy rates. In evaluating policy impact, observational studies alone may not be able to account for background trends and other events. We aimed to evaluate the impact of England's Teenage Pregnancy Strategy on pregnancy and birth rates using natural experimental methods.

Methods Women aged under-20 and living in England during the intervention period were the target population. UK pregnancy rates were taken from Office of National Statistics and Information Services Division Scotland reports for years 1992 2016. We compared under-18 pregnancy rates in England with Scotland and Wales as controls using interrupted time series methods. Observed level and trend changes in controls at 1999 were used to predict a 'No Strategy' England. We compared under-18 birth rates and under-20 pregnancy rates of England with European and English-speaking high-income countries using synthetic control methods. Estimates of births were taken from the Human Fertility Database, estimates of population from the Human Mortality Database and abortions from the European Health Information Gateway, supplemented from national statistics bodies, for years 1990-2013. 